\title{
DESENVOLVIMENTO E IMPLANTAÇÃO DE PROPOSTAS PARA A FORMALIZAÇÃO DE PROCESSOS DE MANUFATURA DE UMA EMPRESA FABRICANTE DE DUTOS INDUSTRIAIS EM NOVA IGUAÇU/RJ
}

1 Pesquisador Independente, Brasil.

\author{
A. L. Germano ${ }^{1 *} ;$ F.O. Araujo ${ }^{2 *}$
}

2 Universidade Federal Fluminense (UFF), Escola de Engenharia | Departamento de Engenharia de Produção |

Programa de Pós-Graduação em Sistemas de Gestão, Niterói, RJ, Brasil.

* fernandoaraujo@id.uff.br

\author{
Artigo submetido em 17/10/2016 e aceito em 01/09/2017
}

\section{RESUMO}

O presente estudo é realizado em uma empresa de pequeno porte, fabricante de dutos industriais para ar condicionado, situada no município de Nova Iguaçu/RJ. Essa empresa tem experimentado problemas de variabilidade em seus produtos finais, muitos dos quais relacionados com a ausência de padronização e formalização dos seus processos. Nesse sentido, objetivo deste trabalho é o de analisar, propor melhorias, implementar e verificar o resultado das ações orientadas à formalização nos processos de gestão de manufatura e de planejamento e controle da produção (PCP). Em termos metodológicos, realiza-se uma pesquisa participante, incluindo observação sistemática e conversas informais com colaboradores e gestores, no sentido de identificar oportunidades de aprimoramento nos processos. Para a modelagem dos processos, análise e proposição de novos processos, utiliza-se o software Bizagi. Como resultados, após as propostas de novos processos, sua implantação e validação na empresa estudada, o estudo, por meio da mensuração dos indicadores corporativos, evidenciou que a formalização de processos foi relevante prática para o aprimoramento do desempenho operacional na empresa, oferecendo-se como possível inspiração para pequenas empresas de manufatura que experimentem problemas similares.

\section{DEVELOPMENT AND IMPLEMENTATION OF PROPOSALS FOR THE FORMALIZATION OF MANUFACTURING PROCESSES IN AN INDUSTRIAL DUCT MANUFACTURER IN NOVA IGUAÇU/RJ} \begin{abstract}
This study takes place in a small scale company, which manufactures industrial ducts for HVAC systems, and is located in the town of Nova Iguaçu, Rio de Janeiro State. This company has experienced variability problems in its final products, many of which are related to the absence of standardization and formalization of its processes for manufacturing management, and production planning and control (PPC). In methodological terms, a participatory research is conducted, which includes the systematic observation and informal dialogue with collaborators and managers, aiming to identify opportunities to fine-tune the
\end{abstract}

processes. The designing of processes, as well as the analysis and proposal of new processes, is handled through the Bizagi software. As for the results, following the proposals of new processes, their implementation and validation within the company researched, the study, through the measurement of corporate indicators, showed that the formalization of processes was a relevant practice towards the improvement of operational performance of the company, and presents itself as a possible inspiration for small manufacturing companies that experience similar problems.

KEYWORDS: Formalization of business processes; Production Planning and Control (PPC); Industrial duct production. 


\section{INTRODUÇÃO}

O presente estudo é realizado com inspiração no caso uma empresa de pequeno porte e de base fabril, fundada em 2004, que produz dutos de aspersão de resíduos sólidos flutuantes e de ar condicionado industrial, notadamente para plantas de processos contínuos ou discretos. A empresa localiza-se na cidade de Nova Iguaçu, no estado do Rio de Janeiro. Em seu primeiro ano de operação, possuía em seu quadro de funcionários 14 profissionais, sendo três na área administrativa e 11 na produção. Em 10 anos de mercado, portanto no final de 2015, a empresa percebeu um representativo aumento do número de colaboradores, contando com 44 profissionais, sendo 34 na produção e 10 na área administrativa.

Se por um lado o crescimento também foi notado em termos de faturamento e número de novos projetos, por outro, os métodos de gestão de operações não acompanharam esse desenvolvimento, sendo recorrentes as reclamações por parte de clientes no que concerne à conformidade da entrega do produto final, especialmente, em termos de qualidade, acabamento, funcionalidade e prazos de entrega.

Em observações in loco e conversas com gestores e funcionários, dois problemas ficam bastante evidentes, a saber: o primeiro refere-se aos processos da empresa, que são essencialmente informais e tácitos, e por não terem sido formalizados através de procedimentos operacionais ou instruções de trabalhos, faz com que algumas etapas relevantes do processo produtivo, sejam realizadas com uma variabilidade deletéria. Em outras palavras, os trabalhadores das operações são os únicos possuidores do modus operandi da atividade-fim da empresa, sendo a conformidade da tarefa ou do produto final é-uma incógnita, pois, dependendo da variação imposta em cada atividade não há garantia de conformidade no produto final.

O segundo problema refere-se ao sistema de gestão do planejamento e controle da produção (PCP), que por sua vez impacta diretamente no Processo de Manufatura da empresa. Foram reportados eventos de o setor de compras ser acionado, de maneira reativa, somente quando o almoxarifado verifica a falta da matéria-prima. Não há controle de estoque mínimo, nem de estoque de segurança. Algumas vezes, a falta de alguma matéria-prima ou insumo, só é detectada durante a fabricação do produto. A situação de não haver controle do planejamento da produção, faz com que constantemente o prazo de entrega dos produtos não seja cumprido pelo fato de a manufatura ter sido paralisada pela falta de matéria-prima.

No sentido de contribuir para a melhor compreensão da problemática e para com o aprimoramento do desempenho da organização em tela, o presente estudo tem como objetivos: [1.] identificar os subprocessos-chave ligados ao macro processo de gerenciamento do PCP, em especial àqueles diretamente relacionados à manufatura dos dutos industriais, visando verificar como são executados; [2.] identificar os aspectos a serem aprimorados referentes aos processos estudados, e; [3.] formalizar padrões tácitos das operações, transformando-os em padrões explícitos através de registros e procedimentos, quando necessário. Para a entrega desses objetivos, o estudo busca amparo na literatura técnico-científica de gestão por processos e de planejamento e controle da produção, visando a aprimorar o arcabouço analítico-propositivo para a compreensão empírica dos fenômenos a serem tratados por meio da abordagem de pesquisa participante.

Em termos de sua estrutura, o estudo está subdividido em cinco seções, onde na primeira, são apresentados o contexto, o problema e os objetivos da investigação. Na seção 2 é feita uma revisão da literatura técnico-científica, evidenciando os principais conceitos capazes de fundamentar a pesquisa. A seção 3 descreve a metodologia empregada na pesquisa. Na seção 4, com base em investigação empírica, são apresentados resultados e discussões. Ressalta-se que as 
propostas foram implantadas e validadas pelo corpo de diretores da empresa estudada. Na seção 5, são relatados os resultados e sugestões de melhorias.

\section{REVISÃO DA LITERATURA}

Esta seção tem o objetivo de fundamentar os assuntos centrais a serem analisados no decorrer deste estudo. Deste modo, a seguir, apresentam-se discussões acerca de gestão de processos de negócio, mapeamento de processos, formalização de processos, planejamento e controle da produção e gestão de mudanças. Como para além da questão técnica, o objeto deste estudo também prevê mudanças organizacionais e comportamentais na implantação das propostas, tanto por parte de gestores, como dos colaboradores, adicionalmente são discutidas algumas características relacionadas à gestão de mudanças e as possíveis resistências que podem surgir em um ambiente em transformação.

\subsection{Gerenciamento de Processos de Negócio}

Para Nunes e Faccio (2014), as empresas devem adaptar seus processos e modelos de negócio para sobreviver às transformações do mercado. Conforme Knoff (2014), os processos organizacionais, também conhecidos como processos de negócio, tornaram-se estruturas fundamentais para o gerenciamento das organizações modernas.

Para a ABPMP - Association of Business Process Management Professionals (2014), o gerenciamento de processos de negócio ou BPM (Business Process Management), representa uma nova forma de visualização das operações do negócio, que extrapola a visão das estruturas funcionais tradicionais. Segundo Gonçalves (2000), esta nova abordagem engloba o trabalho executado para entregar o produto ou serviço do processo, independente de quais áreas funcionais estejam envolvidas. Para Jeston e Nelis (2008), em termos operacionais, a abordagem BPM tem início em um nível mais alto do que o nível que realmente realiza o trabalho, para depois subdividir-se em subprocessos que devem ser realizados por uma ou mais atividades (fluxos de trabalhos) dentro das funções do negócio. Desta forma, para a (ABPMP, 2014), estabelece-se que processo esteja para atividade, assim como fluxo de processo está para fluxo de trabalho (Figura 1).

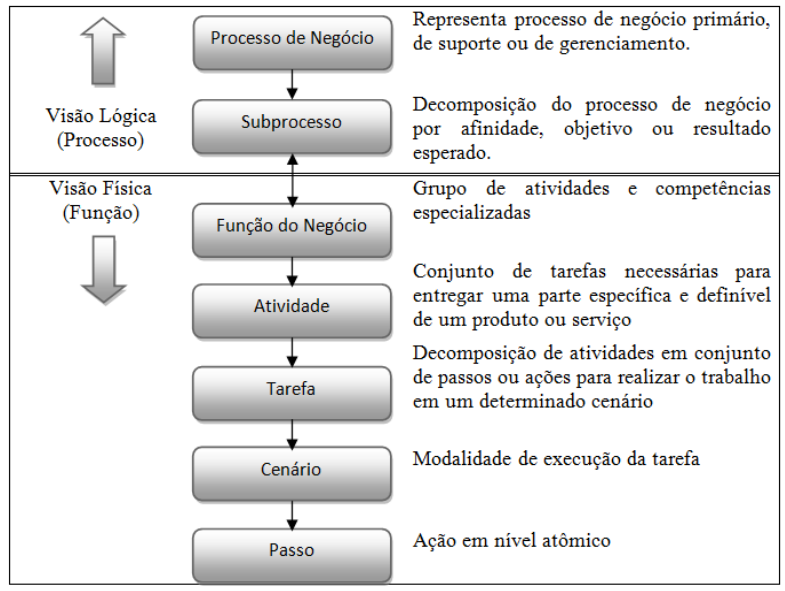

Figura 1 - Processo orquestrado as tarefas Fonte: ABPMP (2014. 33 p)

As definições dos termos "negócio e processo de negócios", adotada pela (ABPPM, 2014), são descritas como: 
- Negócio: refere-se a pessoas que interagem para executar um conjunto de atividades de entrega de valor para os clientes e gerar retorno aos stakeholders. Negócio abrange todos os tipos de organizações, de qualquer porte ou segmento, que visem (ou não) aos lucros, públicas ou privadas.

- Processo de Negócio: refere-se a um trabalho que entrega valor aos clientes ou apoia/gerencia outros processos. Este trabalho pode ser desenvolvido de ponta a ponta, interfuncional ou até mesmo interorganizacional. O entendimento do que é trabalho ponta a ponta interfuncional é fundamental, pois envolve todo o trabalho, ultrapassando limites funcionais necessários para a entrega dos valores aos clientes.

\subsection{Mapeamento de Processo}

Segundo Kipper (2011), o mapeamento de processo é uma ferramenta gerencial e de comunicação, que também auxilia a organização a visualizar claramente os pontos fracos os quais devem ser melhorados, tais como: complexidade na operação, custos, gargalos, falhas de integração, atividades redundantes, tarefas de baixo valor agregado, retrabalhos, excesso de documentação e aprovações, além de ser uma excelente forma de melhorar o entendimento sobre os processos e aumentar o desempenho do negócio.

Para Peinado e Graeml (2007), o mapeamento é o primeiro passo para a padronização das operações. O objetivo é conhecer o processo em seu formato atual, para que seja traçado um fluxo preliminar das atividades. De acordo com Neumann (2013), uma das maneiras mais eficazes de mapeamento de processos, é com a utilização de fluxogramas, pois esta ferramenta permite as seguintes aplicações: [1.] melhorar a compreensão do processo de trabalho; [2.] evidenciar como o trabalho deve ser feito, e/ ou [3.] criar um padrão de trabalho ou uma norma de procedimento.

Embora não exista um conjunto universal de símbolos utilizados para um determinado tipo de processo, existem alguns que são comumente utilizados (Quadro 1).

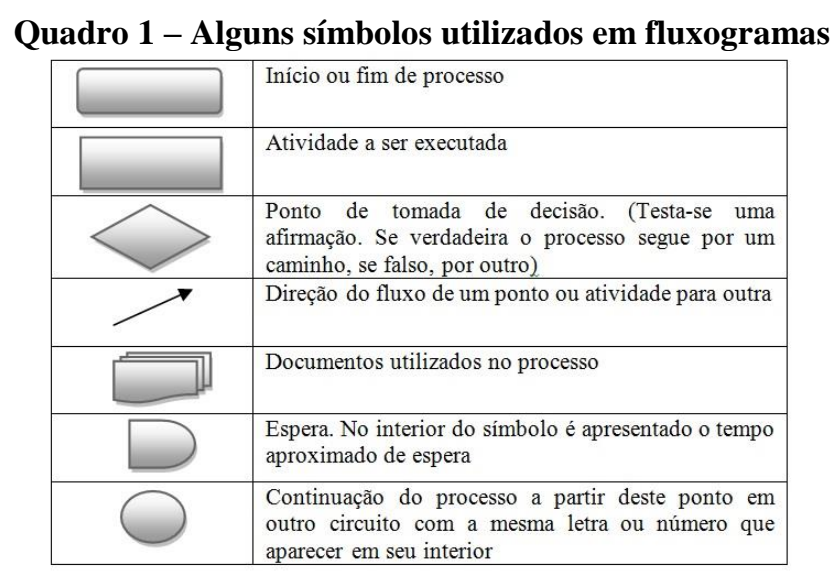

Fonte: Peinado e Graeml (2007, 539 p)

Para Peinaldo e Graeml (2007), o fluxograma é um diagrama utilizado para representar a sequência dos processos, através de símbolos gráficos. Os símbolos proporcionam uma melhor visualização do funcionamento do processo, ajudando no seu entendimento. No gerenciamento de processos, tem como objetivo garantir a qualidade e aumentar a produtividade, através da documentação do fluxo das atividades, utilizando diversos símbolos diferentes para identificar os diferentes tipos de atividades. 
A partir do processo mapeado, pode-se fazer a análise crítica do fluxograma, identificando a existência de aspectos a serem melhorados no fluxo de trabalho. A Figura 2 ilustra a análise crítica de um processo.

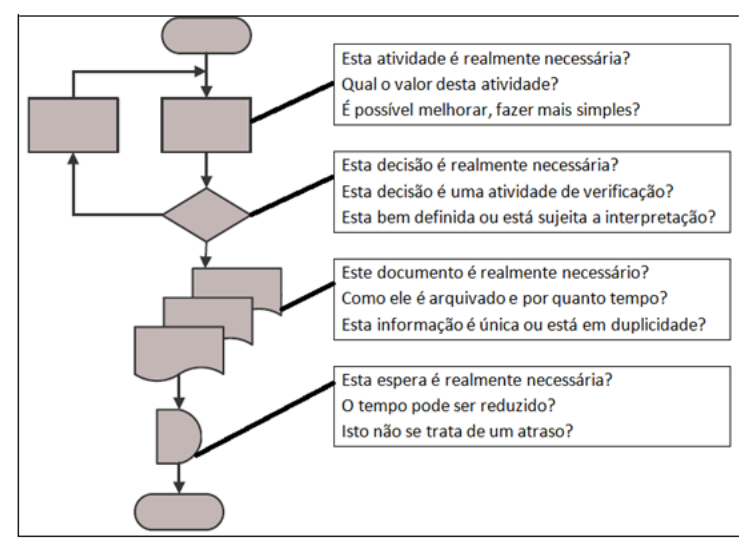

Figura 2 - Análise crítica de um processo Fonte: Peinado e Graeml (2007, 541 p)

\subsubsection{Formalização de Processos}

Albuquerque (2012) define a organização dos processos como sendo representações de padrões de ação recorrentes, isto é, como descrições de modos de agir que se repetem ao longo do tempo em uma organização.

\subsection{Planejamento e Controle da Produção}

Para Slack et al (2009), a administração da manufatura ou administração de operações é definida como a função administrativa responsável pelo estudo e pelo desenvolvimento de técnicas de gestão da manufatura de bens e serviços. Para os autores, a função manufatura é a razão de existir das organizações, contudo, a estratégia da manufatura não pode ser dissociada do Planejamento da Produção e do seu respectivo controle. A Figura 3 ilustra, genericamente, a forma como se dá o fluxo de informações entre as necessidades dos clientes, processo produtivo e processo de fornecimento de matéria prima.

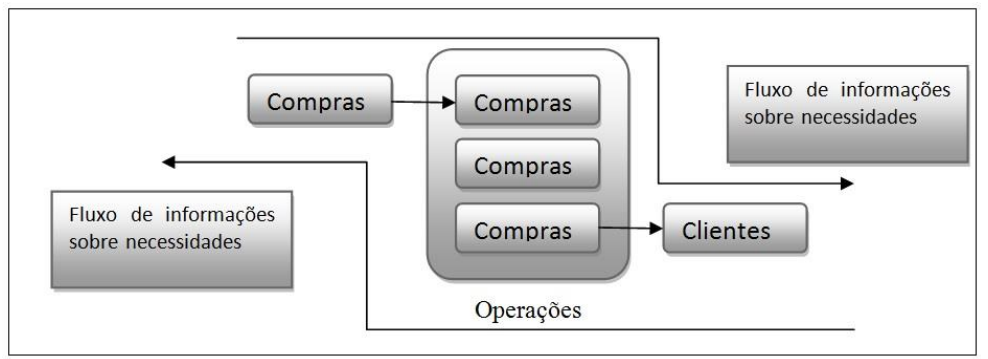

Figura 3 - Fluxo de informações genérico entre processos Fonte: Slack et al (2009, 303 p)

Segundo Correa e Gianesi (2007), o planejamento e controle da produção (PCP), tem a função de coordenar um conjunto de atividades intersetoriais, que possuem o objetivo de suportar o processo de manufatura. Torna-se então necessário comunicar aos departamentos de manufatura quais operações devem ser executadas em cada dia para resultar nos produtos finais desejados. Os sistemas de planejamento e controle de produção são sistemas que provêm informações de diversas áreas do sistema de manufatura, e suportam o gerenciamento eficaz do fluxo de materiais, da 
utilização da mão de obra e dos equipamentos, à coordenação das atividades internas, passando a ser agente para a integração da manufatura.

Para Tubino (2007), o diferencial para que as empresas de base industrial obtenham sucesso, está no controle eficiente do PCP, onde a estratégia da gestão de manufatura deve estar intimamente ligada à estratégia de crescimento da organização. Ainda segundo o autor, o PCP participa do planejamento estratégico da manufatura, formulando o Plano da Manufatura, que define, em linhas gerais, o caminho a ser seguido pela produção, relacionando as necessidades brutas de mão-de-obra, equipamentos e materiais para atender à previsão de vendas do Plano de Marketing (Vendas), em consonância com o Plano Financeiro.

Para Bremer e Lenza (2000), a gestão de produção deve ser estruturada de acordo com as restrições existentes em cada tipo de sistema produtivo. Essas quatro tipologias básicas de produção definem ou direcionam grande parte das atividades que compõem o processo de Gestão da Produção. São elas:

- Make to Stock (Produção para Estoque) - É caracterizado por produzirem itens padronizados e com previsão de demanda. Este sistema possui rapidez na entrega uma vez que os itens estão prontos no estoque. Em contrapartida, o custo para a manutenção do estoque tende a encarecer esta operação.

- Assembly to Order (Montagem sob Encomenda) - É caracterizado pela existência de subconjuntos, grandes componentes e materiais diversos são armazenados até o recebimento dos pedidos dos clientes contendo as especificações dos produtos finais.

- Make to Order (Produção sob Encomenda) - É caracterizado pela liberdade de influência do cliente na etapa inicial do projeto. Neste tipo de sistema, os produtos são geralmente únicos.

- Engineering to Order (Engenharia sob Encomenda) - É caracterizado por ser quase uma extensão do MTO, com o projeto do produto sendo feito quase que totalmente baseado nas especificações do cliente. Os produtos são altamente customizados e o nível de interação com o cliente é intensa.

Quadro 2 - Ambientes de manufatura

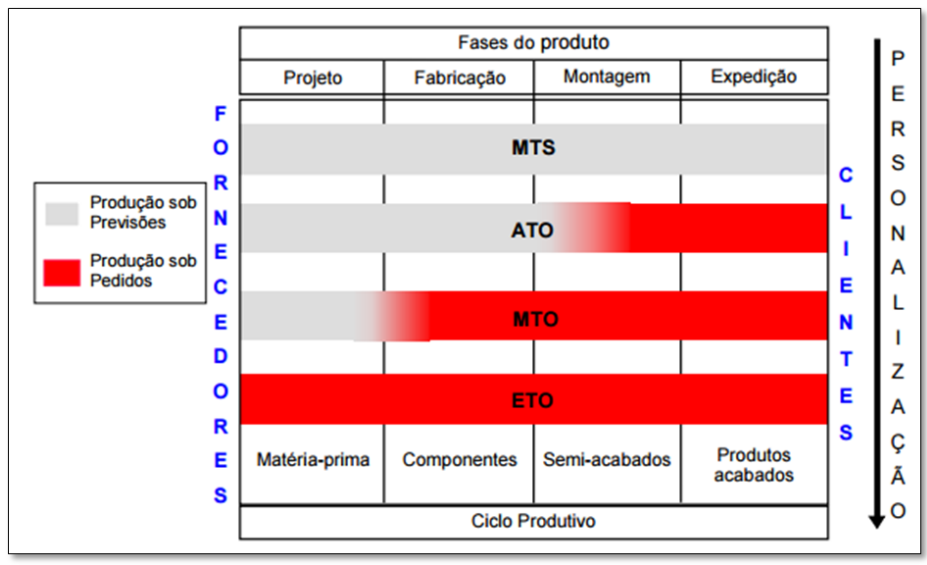

Fonte: Bremer e Lenza (2000, 274 p)

\subsection{Gestão da Mudança}

Para Robbins (2005), resistências às mudanças é um tema que não pode ser ignorado, quando se trata de mudanças organizacionais. A resistência às mudanças possibilita o surgimento de pontos de atenção no processo de transformação, como a tentativa de previsibilidade e de estabilidade do comportamento organizacional a fim de impedir um estado de caos generalizado e 
uma ruptura brusca a cada nova iniciativa. Além disso, a resistência possibilita a oportunidade de pensar novos modelos de trabalho gerando discussões saudáveis e provocando que uma decisão mais madura emerja.

Para Senge et al (1999), gerenciar mudanças significa identificar os processos que contribuem e prejudicam as tentativas de mudanças. As forças contrárias devem ter suas causas investigadas e na medida do possível, serem eliminadas. As forças que vão ao encontro, ou seja, as forças favoráveis às mudanças devem ser identificadas e fortalecidas. O Quadro 3 ilustra alguns desafios impostos durante os processos de mudanças.

Quadro 3 - Desafios para as mudanças

\begin{tabular}{|l|l|}
\hline \multicolumn{1}{|c|}{ Desafios } & \multicolumn{1}{c|}{ Descrição do desafio } \\
\hline Tempo & Os impactos pela mudança resistem em dedicar tempo para administrá-la \\
\hline Capacitação & Necessidade de desenvolver pessoas e capacitá-las para gerenciar a mudança \\
\hline Motivação da mudança & $\begin{array}{l}\text { Necessidade da liderança do projeto de provar e justificar as razões das mudanças para toda } \\
\text { a companhia }\end{array}$ \\
\hline Alinhamento & $\begin{array}{l}\text { Incoerência entre o discurso e valores da mudança e o comportamento, principalmente, por } \\
\text { parte dos entusiastas da mudança }\end{array}$ \\
\hline Confronto & Confronto entre os que acreditam e apoiam e descrentes e resistentes à mudança \\
\hline Autonomia & $\begin{array}{l}\text { Desafio relacionado a confrontos com a infraestrutura e práticas estabelecidas. Possibilidade } \\
\text { de influência na estrutura de governança da organização proporcionando maior autonomia às } \\
\text { unidades da empresa }\end{array}$ \\
\hline Inovação & $\begin{array}{l}\text { Desafio relacionado a confrontos com a infraestrutura e práticas estabelecidas. Dificuldade } \\
\text { em difundir práticas inovadoras pela empresa }\end{array}$ \\
\hline
\end{tabular}
Fonte: Senge et al $(1999,346$ p)

Para Drummond (2015), se uma organização que passa por projetos de transformações não tiver uma cultura propícia a inovações, o processo de transição possivelmente não será suave.

Segundo Chu (2003), todo projeto que altere normas, procedimentos, gestão, tarefas e outras estruturas deve vir acompanhado de uma análise da cultura organizacional existente uma vez que é considerada a variável mais importante para o sucesso de uma implementação. Se a etapa de análise do ambiente pré-mudanças for ignorada, existe a possibilidade de que as mudanças propostas, se implementadas, tornem-se superficiais e de curto prazo.

\section{METODOLOGIA}

Em termos de abordagem, a metodologia utilizada para este estudo é fundamentalmente de natureza qualitativa, analisando um caso específico com o enfoque da pesquisa participante.

Segundo Marconi e Lakatos (2007), a abordagem qualitativa da pesquisa tem como objetivo interpretar e dar significados aos fenômenos analisados sem empregar os métodos e as técnicas estatísticas como base do processo de análise de um problema. Ainda segundo os autores, a abordagem qualitativa possui como objetivos: analisar os cenários estudados; descrever o problema específico; analisar como as variáveis interagem; interpretar os fenômenos e atribuir significados básicos aos conceitos no processo de pesquisa qualitativa.

Em particular, para Brandão (2007), o modelo de pesquisa cujo pesquisador participa da análise da sua própria realidade, pode ser definido como pesquisa participante. Ainda para Brandão (2007), a pesquisa participante pode ser definida como um processo de pesquisa no qual o pesquisador tem capacidade de intervir na análise de sua própria realidade, com vistas a promover uma legítima melhoria por meio da instrumentalização científica. Trata-se, portanto, de uma atividade de pesquisa orientada para a ação. 
Para Demo (2008), o plano deve ser construído socialmente junto aos participantes (objetos de pesquisa), os quais podem auxiliar no apoio a seus objetivos e hipóteses, além da elaboração do cronograma de atividades.

Nessa direção, a partir das conversas iniciais junto aos dois gestores da empresa (Gerente Industrial e Diretor Geral), foram definidos os dias e horários nos quais a pesquisa poderia ser realizada, sem que houvesse prejuízos à rotina da organização. Assim, ao longo de 6 meses, entre outubro de 2014 e novembro de 2015, foram realizadas 28 visitas à empresa, com diálogo técnicoreflexivo sobre os processos-chave do negócio com os citados gestores, além de 7 colaboradores todos com pelo menos 8 anos de empresa, e atuação nos níveis tático e operacional, dos setores de manufatura e PCP.

\subsection{Procedimentos metodológicos da pesquisa empírica}

Para além da necessária fundamentação teórica processos de negócio, cumpre destacar que o levantamento dos processos de trabalho no momento inicial da investigação, e sua consequente fluxogramação, levou em consideração os ensinamentos de Oliveira (2002), quando afirma que:

\footnotetext{
"É importante ressaltar que os fluxogramas procuram mostrar o modo pelo qual as coisas são feitas, e não o modo pelo qual o chefe diz aos funcionários que a façam; não a maneira segundo o qual o chefe pensa que são feitas [...] representam, portanto, uma fotografia real de uma situação estudada." (OLIVEIRA, 2002: 271)
}

Sendo assim, para os processos-chave de manufatura e de PCP, foram feitas representações da sequência descrita pelos trabalhadores, comparando essa descrição com a prática observada pelos pesquisadores, utilizando como suporte gráfico o software Bizagi Process Modeler (software livre, disponível para download em http://www.bizagi.com), desenvolvido para proporcionar a diagramação de processos complexos, definir regra da estrutura do negócio, ordenar outras aplicações e definir interface do usuário).

Nesse sentido, tendo em vista os apontamentos da literatura e definidas as condições de contorno para o acesso ao campo, foram contempladas as seguintes atividades na investigação empírica: [1.] identificação da utilidade de cada etapa do processo mencionado versus praticado pelos trabalhadores; [2.] conversas com os gestores no sentido de observar oportunidades de aprimoramento das práticas administrativas para racionalização dos processos; [3.] verificação das vantagens em alterar a sequência, incorporar ou eliminar atividades, e; [4.] desenvolvimento de propostas de formalização de processos para o aprimoramento da qualidade nos produtos, sucedida de treinamentos para amortecimento das mudanças futuramente introduzidas. A Figura 4 os procedimentos adotados.

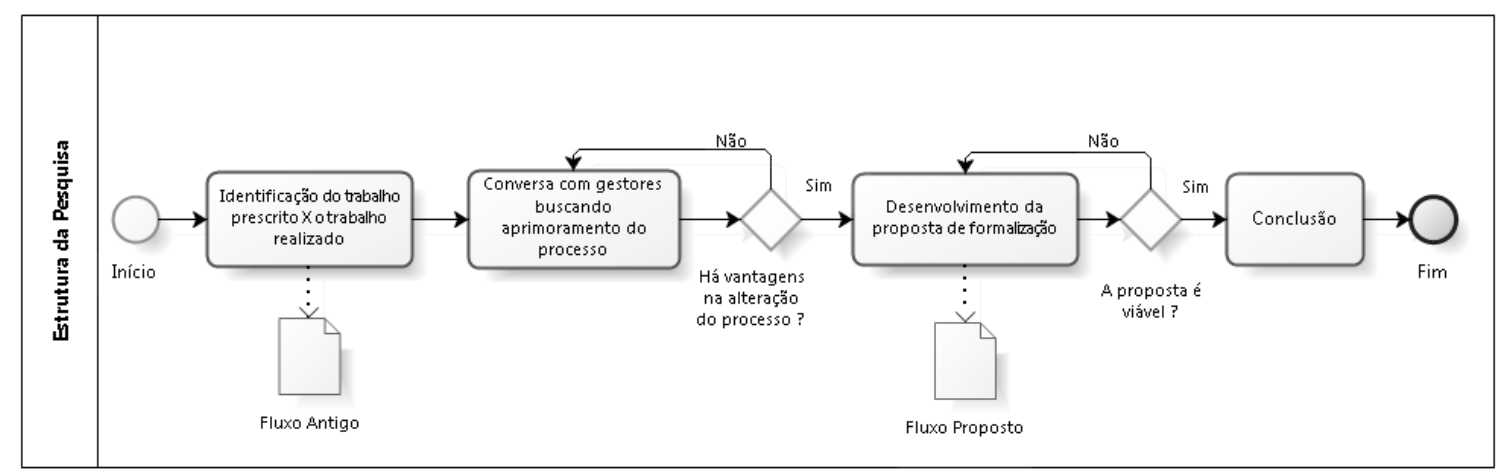

Figura 4 - Procedimentos da pesquisa empírica

Fonte: Elaborada pelos autores (2015) 


\section{RESULTADOS}

\subsection{Caracterização da empresa estudada: ambiente administrativo e de manufatura}

De modo a contribuir para melhor entendimento das condições de contorno da organização estudada, antes das discussões dos resultados, é importante a oferta de informações adicionais relacionadas à empresa, visando à melhor compreensão do ambiente corporativo, com a evidenciação das propostas de melhorias em seus processos de negócio.

A empresa possui em seu quadro de colaboradores 44 pessoas, sendo 10 administrativos (incluindo os dois sócios) e 34 operacionais. Mais de $72 \%$ de seus colaboradores possuem nível médio de ensino. Visando ao aprimoramento na formação do quadro de pessoal, os colaboradores que não possuem o ensino médio completo, e mostram interesse em concluí-lo, recebem por parte da empresa estímulos financeiros, como o acréscimo em seus vales-transportes para o deslocamento trabalho-escola-residência (caso haja necessidade). Esta medida teve o objetivo de incentivar aos colaboradores a retomarem seus estudos. A resposta a esta medida foi que $40 \%$ dos colaboradores retornaram e concluíram o ensino médio. Novas contratações obedecem ao critério de que os candidatos tenham no mínimo o ensino médio completo.

Em relação à faixa etária, mais de $75 \%$ dos colaboradores encontra-se abaixo dos 34 anos. A taxa de rotatividade (turn over) dos colaboradores é baixa. Segundo dados apurados, $85 \%$ dos colaboradores possui mais de cinco anos de trabalho na empresa, o que contribui para a conformação de uma cultura organizacional estável, com baixo nível de mudanças.

Conforme discutido previamente, a empresa utiliza no ambiente de manufatura o sistema MTO (make to order) e tem seu foco na fabricação de dutos e ventiladores industriais. Os dutos possuem formas geométricas diferenciadas (oval, retangular, quadrado e redondo, conforme ilustra a Figura 5), contudo, em termos funcionais, sua utilização é similar.

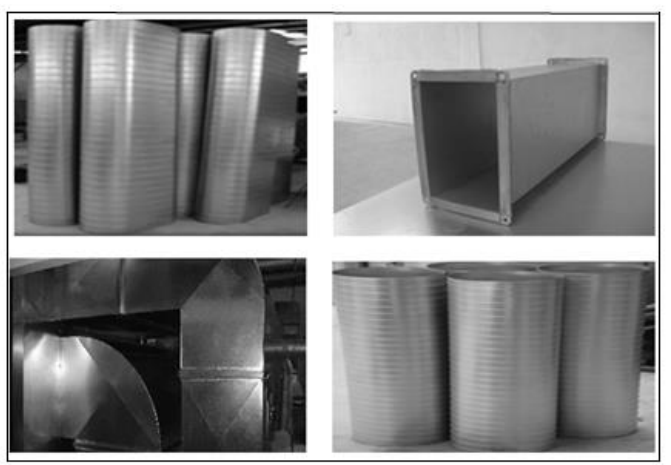

Figura 5 - Tipos de dutos fabricados

Fonte: Acervo fotográfico da empresa estudada (2015)

Os dutos têm a finalidade de conduzir ar, mas também podem ser utilizados para conduzir sólidos "leves" através do sistema de sopro. Um exemplo deste tipo de aplicação pode ser encontrado nas empresas de fabricação de produtos eletrônicos que utilizam isopor como material de proteção mecânica dentro das embalagens. O isopor é conduzido até o setor de embalagem, através de um sistema de dutos. Considerando que a empresa adota um sistema de manufatura puxado por encomendas singulares de clientes (cada duto possui característica técnicas específicas, sendo customizado de acordo com as particularidades de cada contratante), por meio da interação com os clientes, foram relatados um conjunto de não conformidades no produto e/ ou no prazo de 
entrega - o que interfere tanto no nível de serviço da empresa estudada, quanto em uma eventual recomendação ou recompra por parte do cliente.

Com o intuito de evidenciar internamente as causas das não conformidades, foram feitas observações sistemáticas do processo de fabricação dos dutos, além de conversas informais com colaboradores e gestores da empresa. Frutos dessa interação foram diagnosticados os seguintes problemas: indefinição e/ ou excessiva informalidade dos processos produtivos com consequente inobservância de mapeamento das atividades; desbalanceamento da linha de manufatura; ausência de controle sobre o estoque de matéria-prima; inexistência de padronização para conferência dos itens fabricados; ausência de controle dos itens expedidos, e; ausência de padronização na elaboração dos orçamentos de vendas.

Depreende-se desse rol de oportunidades de aprimoramento, que as causas-raízes possuem tanto naturezas técnicas (abrangendo aspectos de gestão de operações), quanto são provenientes de questões sociais, envolvendo dimensões instrucionais e culturais dos colaboradores e dos próprios gestores da empresa.

\subsection{Propostas de melhorias dos processos}

Considerando as não conformidades evidenciadas por meio da pesquisa participante, discutem-se nesta seção as sugestões de melhorias, segmentadas tanto por questões de ordem técnica, como também de ordem social. Nesse ínterim, as sugestões serão apresentadas em três etapas: [i.] Formalização dos Processos; [ii.] Gestão de PCP e, [iii.] Gestão da Manufatura.

\subsubsection{Coleta de dados}

Nesta etapa, foram realizadas conversas informais com os executores dos processos e também com os gestores da empresa, investigando como eram realizadas as operações. Ao compararem-se as respostas conferidas por estes dois grupos (executores e gestores), foi possível observar uma diferença significativa na forma pela qual os processos eram visualizados e entendidos por estes dois grupos.

Com estas informações devidamente registradas, a etapa seguinte foi realização do acompanhamento da execução das atividades. Através da técnica de observação direta, foi possível acompanhar, sem intromissão, as atividades sendo realizadas durante as suas rotinas normais. Neste momento foi observado um novo fenômeno: a forma de execução real das atividades, não estava alinhada com a forma pela qual haviam sido relatadas durante as conversas informais.

Neste contexto, observou-se a oportunidade de introduzir nas atividades onde foram observadas as maiores variações, a saber, PCP e manufatura, propostas de mudanças alterando a forma como as operações são executadas, através da racionalização das atividades e da formalização dos processos.

\subsubsection{Diagnóstico da situação do processo do PCP antes das propostas de melhoria}

A Figura 6 ilustra o processo do PCP antes das propostas de melhoria. 


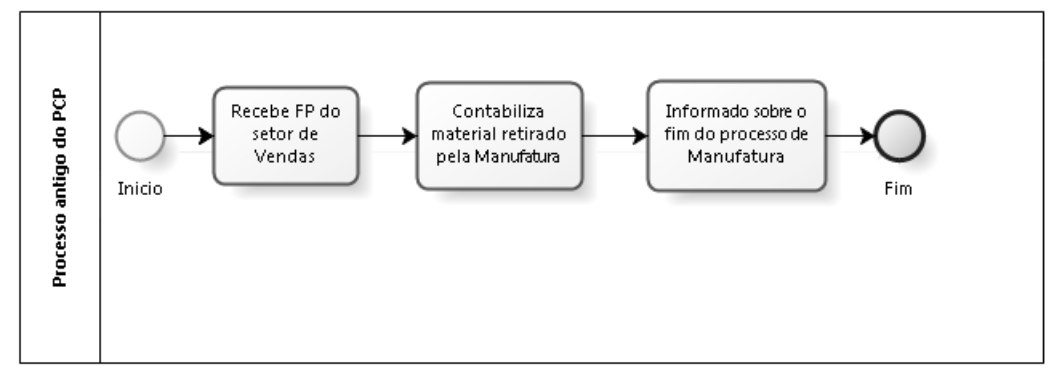

Figura 6 - Processo do PCP

Fonte: Elaborada pelos autores (2015)

Depreende-se da supracitada Figura 6, elaborada a partir da observação sistemática e da conversa com os colaboradores da organização que a situação do processo de PCP apresenta algumas características que contribuem para a falta de controle do estoque. Alguns pontos observados são os seguintes:

- Não há almoxarife: o estoque é aberto e os materiais são requisitados e retirados do estoque pelos próprios operadores da manufatura;

- Não há controle de consumo de material do estoque: quando o setor de vendas realiza uma venda, faz-se o cálculo teórico de todos os materiais que serão consumidos naquela ordem de produção. Não há uma confrontação entre a quantidade de matéria prima que foi especificada e a que realmente foi gasta.

- Não há controle do estoque: o setor de vendas ao realizar uma venda, verifica no sistema a quantidade de matéria prima existente no sistema. Esta informação nunca é verdadeira, o que sempre provoca atrasos nas entregas por falta de matéria prima.

\subsubsection{Situação do processo de manufatura antes das propostas de melhoria}

Assim como no processo anterior, a Figura 7 representa o processo de manufatura antes das propostas de melhoria.

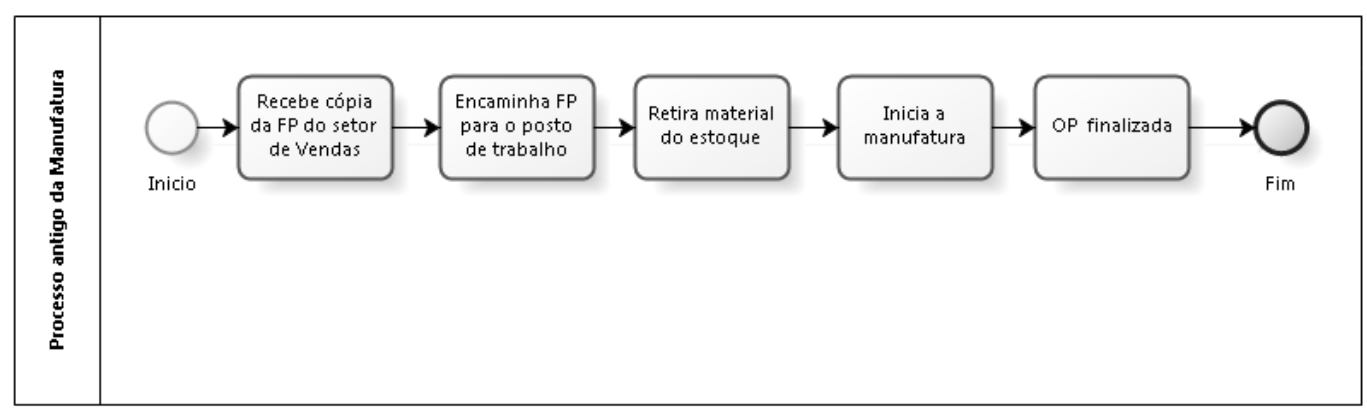

Figura 7 - Processo da Manufatura

Fonte: Elaborada pelos autores (2015)

Depreende-se da Figura 7, elaborada a partir da observação sistemática e da conversa informal com os colaboradores da organização que o processo de manufatura também apresenta algumas características que comprometem o fluxo normal das atividades da empresa. Alguns pontos observados serão relacionados abaixo:

- Falta de entendimento comum entre os itens a serem fabricados: como a maior parte dos itens a serem fabricados não possuem desenhos, mas apenas descrições técnicas, várias situações de 
não conformidade entre o que foi especificado pelo setor de vendas e o que foi efetivamente vendido.

- Não há controle de qualidade: Os itens são fabricados e expedidos sem que haja qualquer observação dos requisitos especificados na Folha de Produção (FP).

- Não há controle das Ordens de Produção (OP): As OP são encerradas e esta informação não é repassada ao aos setores de Vendas, Expedição e Contas a Pagar. As áreas de produção ficam tomadas de obras já finalizadas, os clientes não recebem suas mercadorias e a empresa não consegue faturar obras finalizadas.

\subsection{Propostas de formalização dos processos}

A partir da coleta de dados realizada na etapa de identificação dos processos, foi possível identificar a forma mais adequada para a realização de cada tarefa. Com isto eliminam-se as duplicidades de atividades, reduz-se o custo em controles ineficientes e, principalmente, observamse oportunidades de aprimoramento, tornando os processos mais rápidos, seguros e eficientes (KLUSKA et al, 2015).

A técnica adotada para a formalização dos processos é a ferramenta da qualidade denominada 5W1H. Para Martins e Laugeni (2009), o 5W1H está associado ao desenvolvimento de um plano de ação que se baseia em seis perguntas, a saber: What (o que?), Who (quem?), When (quando?), Where (Onde?), Why (Por que?) e How (como?). Sua utilização visa a identificar as tarefas, ações e outros aspectos necessários para a execução de um trabalho.

\subsection{Formalização do Processo de PCP}

A formalização proposto para o processo de PCP foi dividida em dez subprocessos, a saber: receber folha de produção (FP - Folha de Produção: Documento técnico onde estão especificados todos os itens que devem ser manufaturados); gerar lista de material (LM); reservar material para a obra; encaminhar pedido de compra; receber fisicamente o material; entrar com o material no estoque; informar a chegada do material; encaminhar Nota Fiscal (NF) para o setor de contas a pagar; pagar material a Manufatura, e; estornar material ao estoque (Sliter ou chapa).

Dentre as mudanças propostas, a formalização das atividades do PCP, certamente pode oferecer significativas contribuições para a empresa, pois esta formalização estabelece conceitos novos para a organização como Lista de Material e MRP. A formalização deste processo evidencia a necessidade de controle de materiais em estoque e também o controle dos itens necessários para a fabricação de cada um dos produtos que a empresa fabrica.

Foram propostos também conceitos de reserva e transferência de material. Está prática visa a retirar do estoque principal da empresa, produtos/matéria-prima que já estejam, através do processo de vendas, comprometidos com algum processo de fabricação. Esta medida também cerceia que produtos/matéria-prima comprometidos sejam visualizados pelo departamento de vendas e sejam comercializados novamente. Outro conceito implantado foi o de estoque mínimo. Através de informações (lead time) obtidas junto ao departamento de compras, foi estabelecido um estoque mínimo para cada item. Quando determinado item, atingir o NEI (Nível de Estoque Ideal), o departamento de compras pode ser acionado pelo almoxarifado para providenciar o ressuprimento do estoque.

O Quadro 4 ilustra a proposta de formalização do processo proposto para o PCP Planejamento e Controle da Produção. 
Quadro 4 - Formalização do processo de PCP

\begin{tabular}{|c|c|c|c|c|c|c|}
\hline \multicolumn{7}{|c|}{ Processo de Planejamento e Controle da Produção - PCP } \\
\hline \# & O que? & Quem? & Como? & \begin{tabular}{|c|} 
Quando? \\
\end{tabular} & Onde? & Por que? \\
\hline 1 & $\begin{array}{l}\text { Receber Folha de } \\
\text { Produção (FP) }\end{array}$ & Almoxarife & $\begin{array}{l}\text { Pessoalmente, anotando } \\
\text { na FP a data do } \\
\text { recebimento }\end{array}$ & $\begin{array}{l}\text { Após supervisor da } \\
\text { manufatura analisar a Folha } \\
\text { de Produção(FP) }\end{array}$ & $\begin{array}{l}\text { Sala da } \\
\text { supervisão da } \\
\text { manufatura }\end{array}$ & $\begin{array}{l}\text { Dar início ao processo } \\
\text { suprimento da produção }\end{array}$ \\
\hline 2 & $\begin{array}{l}\text { Gerar Lista de } \\
\text { Material (LM) }\end{array}$ & Almoxarife & $\begin{array}{l}\text { Através da consulta da } \\
\text { planilha de MRP }\end{array}$ & $\begin{array}{l}\text { Imediatamente após receber } \\
\text { a FP }\end{array}$ & Almoxarifado & $\begin{array}{l}\text { Identificar a necessidade de } \\
\text { compra de material e } \\
\text { atualizar o saldo do estoque } \\
\text { principal }\end{array}$ \\
\hline 3 & $\begin{array}{l}\text { Reservar material } \\
\text { para a obra }\end{array}$ & Almoxarife & $\begin{array}{l}\text { Através de operações no } \\
\text { sistema Prosoft, transfere } \\
\text { o material do estoque } \\
\text { principal para o estoque } \\
\text { da Manufatura (em } \\
\text { processo) }\end{array}$ & $\begin{array}{l}\text { Imediatamente após receber } \\
\text { a LM }\end{array}$ & Almoxarifado & $\begin{array}{l}\text { Identificar a necessidade de } \\
\text { compra de material e } \\
\text { atualizar o saldo do estoque } \\
\text { principal }\end{array}$ \\
\hline 4 & $\begin{array}{l}\text { Encaminhar pedido } \\
\text { de compra }\end{array}$ & Almoxarife & $\begin{array}{l}\text { Pessoalmente, } \\
\text { identificando na RM se o } \\
\text { material é para repor o } \\
\text { estoque ou para } \\
\text { atendimento a uma obra }\end{array}$ & $\begin{array}{l}\text { Após verificar a } \\
\text { necessidade de compra do } \\
\text { item }\end{array}$ & $\begin{array}{l}\text { Dept }^{\circ} \text { de } \\
\text { Compras }\end{array}$ & $\begin{array}{l}\text { Repor estoque/ atender } \\
\text { necessidade da obra }\end{array}$ \\
\hline 5 & $\begin{array}{l}\text { Receber } \\
\text { fisicamente o } \\
\text { material }\end{array}$ & Almoxarife & $\begin{array}{l}\text { Conferindo se as } \\
\text { informações contidas na } \\
\text { ordem de compra (OC) } \\
\text { estão de acordo com as } \\
\text { especificações do } \\
\text { material recebido } \\
\end{array}$ & $\begin{array}{l}\text { Após a compra do material } \\
\text { e sua chegada }\end{array}$ & Almoxarifado & $\begin{array}{l}\text { Dar entrada no estoque e } \\
\text { atender a Manufatura }\end{array}$ \\
\hline 6 & $\begin{array}{l}\text { Entrar com o } \\
\text { material no estoque }\end{array}$ & Almoxarife & $\begin{array}{l}\text { Através de operações no } \\
\text { sistema Prosoft }\end{array}$ & $\begin{array}{l}\text { Após a conferência e } \\
\text { aceitação do material }\end{array}$ & Almoxarifado & $\begin{array}{l}\text { Dar entrada no estoque e } \\
\text { alimentar o sistema de } \\
\text { Contas a Pagar }\end{array}$ \\
\hline 7 & $\begin{array}{l}\text { Informar a chegada } \\
\text { do material }\end{array}$ & Almoxarife & $\begin{array}{l}\text { Pessoalmente, } \\
\text { informando o número da } \\
\text { ordem de compra que } \\
\text { chegou }\end{array}$ & $\begin{array}{l}\text { Após receber o material e } \\
\text { lançá-lo no estoque }\end{array}$ & $\begin{array}{l}\text { Departamento } \\
\text { de Compras }\end{array}$ & $\begin{array}{l}\text { Encerrar o processo de } \\
\text { compra do item }\end{array}$ \\
\hline 8 & $\begin{array}{l}\text { Encaminhar Nota } \\
\text { Fiscal (NF) para o } \\
\text { Contas a Pagar }\end{array}$ & Almoxarife & $\begin{array}{l}\text { Pessoalmente, } \\
\text { encaminhando o processo } \\
(\mathrm{NF}+\mathrm{OC}+\text { Certificados })\end{array}$ & $\begin{array}{l}\text { Após dar a entrada na } \\
\text { material no estoque e } \\
\text { comunicar ao Dept }^{\circ} \text { de } \\
\text { Compras a chegada do } \\
\text { material }\end{array}$ & $\begin{array}{l}\text { Dept }^{\circ} \text { de Contas } \\
\text { a Pagar }\end{array}$ & $\begin{array}{l}\text { Dar início ao processo de } \\
\text { Contas a Pagar }\end{array}$ \\
\hline 9 & $\begin{array}{l}\text { Pagar material a } \\
\text { Manufatura }\end{array}$ & Almoxarife & $\begin{array}{l}\text { Pessoalmente, entregando } \\
\text { o material solicitado e } \\
\text { posteriormente dando } \\
\text { baixa no item no sistema } \\
\text { Prosoft }\end{array}$ & $\begin{array}{l}\text { Após receber a Requisição } \\
\text { de Material e certificar-se } \\
\text { que o material requisitado } \\
\text { faz parte da LM }\end{array}$ & Almoxarifado & $\begin{array}{l}\text { Dar continuidade ao } \\
\text { processo de manufatura }\end{array}$ \\
\hline 10 & $\begin{array}{l}\text { Estornar material } \\
\text { ao estoque (Sliter } \\
\text { ou chapa) }\end{array}$ & Almoxarife & $\begin{array}{l}\text { Armazenando o material } \\
\text { e através de operações no } \\
\text { sistema Prosoft }\end{array}$ & Após o encerramento da FP & Almoxarifado & $\begin{array}{l}\text { Atualizar o saldo do } \\
\text { estoque }\end{array}$ \\
\hline
\end{tabular}

Fonte: Elaborada pelos autores (2015)

\subsubsection{Proposta de aprimoramento no fluxo de trabalho do PCP}

O fluxo proposto para o processo de PCP está ilustrado na Figura 8. Pode-se observar que houve esmero para a descrição completa das atividades interferentes ao PCP, incluindo interface desse fluxo de trabalho com outras áreas da empresa. O fluxo proposto visa à formalização de fluxos de trabalho tacitamente definidos; eliminações de atividades desnecessárias e de cruzamentos capazes de gerarem retrabalham ou espera, sem repetição das atividades. 


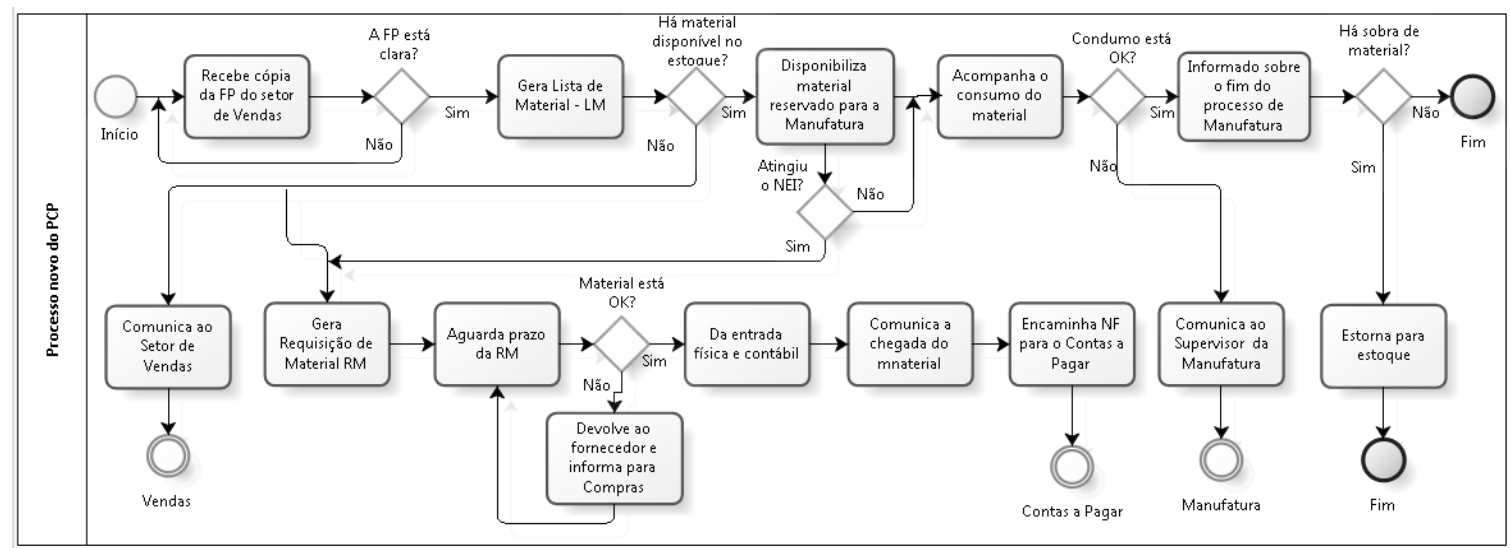

Figura 8 - Fluxograma do PCP

Fonte: Elaborada pelos autores (2015)

\subsection{Formalização do processo de manufatura de dutos}

A proposta de formalização para o processo de produção de dutos foi dividido em 12 subprocessos, a saber: analisar a FP e etiqueta de TAG (Etiqueta de código de barras, com informações do item a ser manufaturado); etiqueta de TAG para o Supervisor da Manufatura; encaminha a FP para o início do processo; requisitar matéria-prima (MP) / material; iniciar a fabricação; comunicar ao encarregado término da operação; devolver MP/material (Sliter ou chapa); comunicar o término da obra ao supervisor de produção; encerrar a FP; comunicar o término da FP ao Departamento de Vendas, e; encaminhar material para a expedição. O Quadro 5 ilustra a formalização proposto para o processo de Produção.

Quadro 5 - Formalização do Processo de Produção

\begin{tabular}{|c|c|c|c|c|c|c|}
\hline \multicolumn{7}{|c|}{ Processo de Manufatura } \\
\hline$\#$ & O que? & Quem? & Como? & Quando? & Onde? & Por que? \\
\hline 1 & $\begin{array}{l}\text { Analisar a FP e } \\
\text { etiqueta de TAG }\end{array}$ & $\begin{array}{l}\text { Supervisor da } \\
\text { manufatura }\end{array}$ & $\begin{array}{l}\text { Verificando as } \\
\text { informações contidas } \\
\text { na FP }\end{array}$ & $\begin{array}{l}\text { Após receber a } \\
\text { documentação do setor } \\
\text { de Vendas }\end{array}$ & $\begin{array}{l}\text { Sala da } \\
\text { supervisão da } \\
\text { manufatura }\end{array}$ & $\begin{array}{l}\text { Mitigar possibilidades de } \\
\text { erros na passagem de } \\
\text { serviço para a Manufatura }\end{array}$ \\
\hline 2 & $\begin{array}{l}\text { Encaminhar FP e } \\
\text { etiqueta de TAG } \\
\text { para o encarregado } \\
\text { da manufatura }\end{array}$ & $\begin{array}{l}\text { Supervisor de } \\
\text { manufatura }\end{array}$ & $\begin{array}{l}\text { Pessoalmente, } \\
\text { ressaltando os } \\
\text { requisitos (prazo, } \\
\text { qualidade, etc.) } \\
\text { contidos na FP }\end{array}$ & $\begin{array}{l}\text { Após lançar dados da } \\
\text { obra no Quadro de } \\
\text { Acompanhamento da } \\
\text { Produção }\end{array}$ & $\begin{array}{l}\text { Sala da } \\
\text { supervisão da } \\
\text { manufatura }\end{array}$ & $\begin{array}{l}\text { Dar início ao processo de } \\
\text { Manufatura }\end{array}$ \\
\hline 3 & $\begin{array}{l}\text { Encaminhar a FP } \\
\text { para o início do } \\
\text { processo }\end{array}$ & $\begin{array}{l}\text { Encarregado da } \\
\text { manufatura }\end{array}$ & $\begin{array}{l}\text { Pessoalmente, } \\
\text { ressaltando os } \\
\text { requisitos contidos na } \\
\text { FP }\end{array}$ & $\begin{array}{l}\text { Após receber a FP e } \\
\text { etiqueta de TAG do } \\
\text { Supervisor da } \\
\text { Manufatura }\end{array}$ & $\begin{array}{l}\text { Posto de } \\
\text { trabalho }\end{array}$ & $\begin{array}{l}\text { Continuar o processo de } \\
\text { Manufatura }\end{array}$ \\
\hline 4 & $\begin{array}{l}\text { Requisitar Matéria } \\
\text { Prima (MP) / } \\
\text { material }\end{array}$ & $\begin{array}{l}\text { Operador do } \\
\text { processo }\end{array}$ & $\begin{array}{l}\text { Entregando ao } \\
\text { almoxarifado a } \\
\text { requisição de MP/ } \\
\text { Material, contendo o } \\
\text { número da FP }\end{array}$ & $\begin{array}{l}\text { Após receber a FP, } \\
\text { preencher a Requisição } \\
\text { de material }(\mathrm{RM}) \mathrm{e} \\
\text { coletar a assinatura do } \\
\text { Encarregado da } \\
\text { Manufatura }\end{array}$ & Almoxarifado & $\begin{array}{l}\text { Continuar o processo de } \\
\text { Manufatura }\end{array}$ \\
\hline 5 & $\begin{array}{l}\text { Iniciar a } \\
\text { fabricação }\end{array}$ & $\begin{array}{l}\text { Operador do } \\
\text { processo }\end{array}$ & $\begin{array}{l}\text { Utilizando as } \\
\text { informações contidas } \\
\text { na FP + a experiência }\end{array}$ & $\begin{array}{l}\text { Após receber a } \\
\text { MP/material } \\
\text { requisitados }\end{array}$ & $\begin{array}{l}\text { Posto de } \\
\text { trabalho }\end{array}$ & $\begin{array}{l}\text { Continuar o processo de } \\
\text { Manufatura }\end{array}$ \\
\hline 6 & $\begin{array}{l}\text { Comunicar ao } \\
\text { encarregado o } \\
\text { término da } \\
\text { operação }\end{array}$ & $\begin{array}{l}\text { Operador do } \\
\text { processo }\end{array}$ & $\begin{array}{l}\text { Devolvendo } \\
\text { pessoalmente a FP } \\
\text { datada e assinada }\end{array}$ & $\begin{array}{l}\text { Após conferir e } \\
\text { identificar com as } \\
\text { etiqueta de TAG os } \\
\text { itens }\end{array}$ & $\begin{array}{l}\text { Posto de } \\
\text { trabalho }\end{array}$ & $\begin{array}{l}\text { Encerrar a FP e se } \\
\text { preparar para iniciar outra } \\
\text { obra }\end{array}$ \\
\hline 7 & $\begin{array}{l}\text { Devolver } \\
\text { MP/material } \\
\text { (Sliter ou chapa) }\end{array}$ & $\begin{array}{l}\text { Operador do } \\
\text { processo }\end{array}$ & $\begin{array}{l}\text { Pessoalmente } \\
\text { entregando os itens ao } \\
\text { almoxarifado }\end{array}$ & $\begin{array}{l}\text { Após encerrar a FP e } \\
\text { constatar que houve } \\
\text { sobra de material }\end{array}$ & Almoxarifado & Iniciar outra obra \\
\hline 8 & $\begin{array}{l}\text { Controlar a } \\
\text { qualidade dos } \\
\text { itens }\end{array}$ & $\begin{array}{l}\text { Operador do } \\
\text { processo }\end{array}$ & $\begin{array}{l}\text { Pessoalmente } \\
\text { checando se os itens } \\
\text { estão conforme } \\
\text { especificado }\end{array}$ & $\begin{array}{l}\text { Após a fabricação de } \\
\text { cada item }\end{array}$ & Manufatura & Ao finalizar cada item \\
\hline
\end{tabular}




\begin{tabular}{|c|c|c|c|c|c|c|}
\hline \multicolumn{7}{|c|}{ Processo de Manufatura } \\
\hline$\#$ & O que? & Quem? & Como? & Quando? & Onde? & Por que? \\
\hline 9 & $\begin{array}{l}\text { Comunicar o } \\
\text { término da obra ao } \\
\text { Supervisor da } \\
\text { Manufatura } \\
\end{array}$ & $\begin{array}{l}\text { Encarregado da } \\
\text { Manufatura }\end{array}$ & $\begin{array}{l}\text { Entregando a FP } \\
\text { finalizada pelo } \\
\text { operador e conferida } \\
\text { por ele }\end{array}$ & $\begin{array}{l}\text { Após por todas as } \\
\text { etiquetas de TAG em } \\
\text { todos os itens da FP }\end{array}$ & $\begin{array}{l}\text { Sala da } \\
\text { supervisão da } \\
\text { Manufatura }\end{array}$ & Finalizar o processo \\
\hline 10 & Encerrar a FP & $\begin{array}{l}\text { Encarregado da } \\
\text { Manufatura }\end{array}$ & $\begin{array}{l}\text { Dando baixa na FP que } \\
\text { está no sistema e } \\
\text { eliminando a obra do } \\
\text { quadro de Manufatura }\end{array}$ & $\begin{array}{l}\text { Após receber a FP do } \\
\text { Operador do Processo }\end{array}$ & $\begin{array}{l}\text { Sala da } \\
\text { supervisão da } \\
\text { Manufatura }\end{array}$ & $\begin{array}{l}\text { Finalizar o Processo de } \\
\text { Manufatura }\end{array}$ \\
\hline 11 & $\begin{array}{l}\text { Comunicar o } \\
\text { término da FP ao } \\
\text { Departamento de } \\
\text { Vendas }\end{array}$ & $\begin{array}{l}\text { Supervisor da } \\
\text { Manufatura }\end{array}$ & $\begin{array}{l}\text { Entregando a FP } \\
\text { finalizada ao vendedor } \\
\text { responsável pela venda }\end{array}$ & $\begin{array}{l}\text { Após encerrar a FP na } \\
\text { Manufatura }\end{array}$ & $\begin{array}{l}\text { Departamento } \\
\text { de Vendas }\end{array}$ & $\begin{array}{l}\text { Dar ciência a setor de } \\
\text { vendas do término da obra }\end{array}$ \\
\hline 12 & $\begin{array}{l}\text { Encaminhar } \\
\text { material para a } \\
\text { expedição }\end{array}$ & $\begin{array}{l}\text { Operador do } \\
\text { processo }\end{array}$ & $\begin{array}{l}\text { Disponibilizando todos } \\
\text { os itens para a } \\
\text { realização da } \\
\text { expedição }\end{array}$ & $\begin{array}{l}\text { Após entregar a FP ao } \\
\text { Supervisor de } \\
\text { Manufatura }\end{array}$ & Expedição & $\begin{array}{l}\text { Finalizar o processo de } \\
\text { Manufatura }\end{array}$ \\
\hline
\end{tabular}

Fonte: Elaborada pelos autores (2015)

Ao receber a FP, o operador fica incumbido de processar a fabricação e montagem dos itens contidos na LM. O único controle sobre o andamento do processo dá-se sobre o próprio operador. Já na fabricação de dutos, os itens são fabricados por diferentes postos de trabalho, o que dificulta o controle da mão-de-obra e das etapas que estão sendo realizadas. Para minimizar este problema, propõe-se a criação do Quadro de Controle da Manufatura ilustrado no Quadro 6.

Quadro 6 - Quadro de Controle da Manufatura

\begin{tabular}{|c|c|c|c|c|c|c|c|c|c|c|c|c|c|c|c|c|c|c|c|c|c|c|c|c|}
\hline \multicolumn{25}{|c|}{ QUADRO DE CONTROLE DA MANUFATURA } \\
\hline \multirow[t]{2}{*}{ PROPOSTA } & \multirow[t]{2}{*}{ ENTRADA } & \multicolumn{2}{|c|}{ DESENHO } & \multicolumn{2}{|c|}{ CORTE } & \multicolumn{2}{|c|}{ MONTAGEM } & \multicolumn{2}{|c|}{$\begin{array}{c}\text { DUTO } \\
\text { REDONTO }\end{array}$} & \multicolumn{2}{|c|}{$\begin{array}{l}\text { DUITO } \\
\text { OVAL }\end{array}$} & \multicolumn{2}{|c|}{$\begin{array}{c}\text { DUTO } \\
\text { TDC }\end{array}$} & \multicolumn{2}{|c|}{ SUPORTE } & \multicolumn{2}{|c|}{ ISOLAMENTO } & \multicolumn{2}{|c|}{ AIR JET } & \multicolumn{2}{|c|}{ PINTURA } & \multicolumn{2}{|c|}{ EMBALAGEM } & \multirow[t]{2}{*}{ SAÍDA } \\
\hline & & 1 & $F$ & $\mathrm{I}$ & $F$ & I & $F$ & $I$ & $F$ & $I$ & $F$ & $\mathrm{I}$ & $F$ & $\mathrm{I}$ & $F$ & 1 & $F$ & I & $F$ & 1 & $F$ & $\mathrm{I}$ & $F$ & \\
\hline & & & & & & & & & & & & & & & & & & & & & & & & \\
\hline & & & & & & & & & & & & & & & & & & & & & & & & \\
\hline
\end{tabular}

Fonte: Elaborada pelos autores (2015)

Neste quadro estão relacionadas todas as etapas de produção possíveis. Esse instrumento visual deve ser posicionado na sala do supervisor de produção, onde estão relacionadas as obras, com as datas de início e fim. Em cada fase do processo de manufatura representado no Quadro de Controle da Manufatura, existem duas colunas identificadas com as letras I e F, onde supervisor de manufatura juntamente com o encarregado de manufatura, pode fazer a programação da manufatura, indicando nas colunas I, o início de cada etapa e na coluna $\mathrm{F}$ preenchida a previsão de fim. O objetivo deste quadro é permitir uma visualização global da situação das obras quanto à data de entrega.

\subsubsection{Fluxograma do processo de Manufatura}

O fluxo proposto para o processo de manufatura, ilustrado na Figura 9, visa a eliminar os óbices verificados durante a etapa de coleta de dados. 


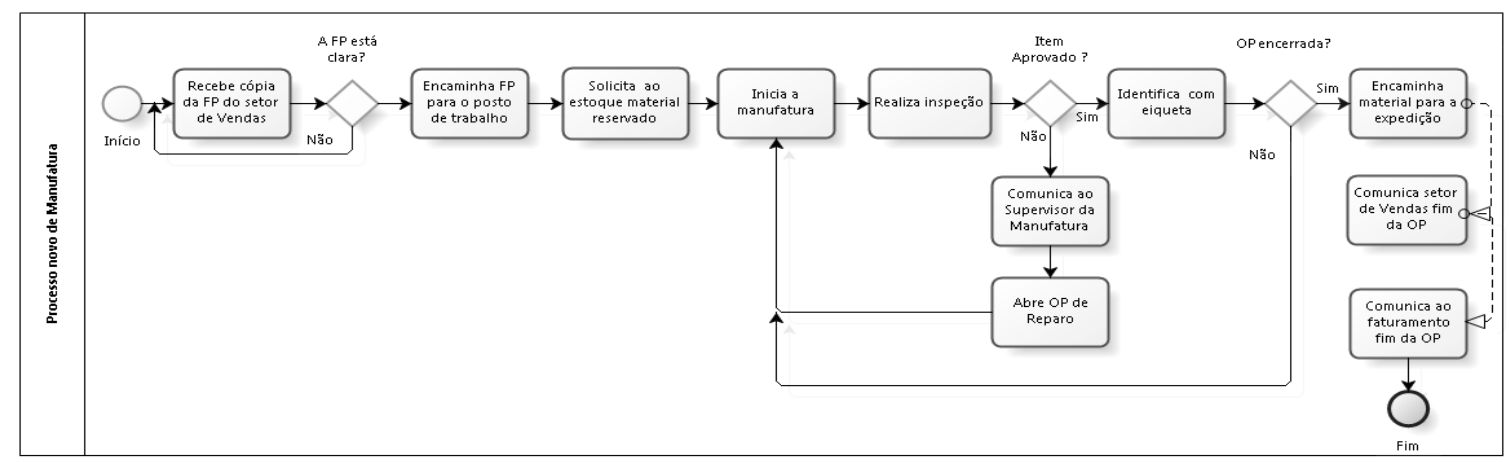

Figura 9 - Fluxograma da Manufatura

Fonte: Elaborada pelos autores (2015)

Dentre as mudanças propostas neste novo fluxo, pode-se observar que foram incluídas questões, como:

- Verificação sobre a clareza da FP: o início do processo de manufatura, conforme descrito anteriormente, estava sujeito a inúmeras falhas devido a problemas com o entendimento sobre o que deveria ser produzido. Após receber a FP, deve haver uma conferência dos itens a serem produzidos e caso haja algum ponto que gere dúvidas, prevê-se o retorno da FP ao setor de vendas para que o ponto seja esclarecido.

- Verificação da qualidade do item: foi proposta uma etapa de inspeção dimensional e visual dos itens produzidos. Após a fabricação de cada duto, prevê-se conferência pormenorizada dos produtos.

- Fim do processo produtivo: foi proposta uma etapa onde o fim da manufatura é comunicado aos setores envolvidos (expedição, faturamento e vendas) para que as devidas providências possam ser tomadas.

\section{Confrontação dos resultados empíricos com a literatura}

As sugestões apresentadas neste trabalho foram aprovadas pela diretoria da empresa, que se dispôs a buscar recursos imediatos para proporcionar implementação das mudanças propostas. A empresa nomeou um Gerente de Projetos responsável por materializar as iniciativas sugeridas na forma de um projeto. O Quadro 7 ilustra o cronograma de trabalho que foi utilizado para a realização das etapas do projeto.

Quadro 7 - Cronograma final do projeto

\begin{tabular}{|c|c|c|c|c|c|c|c|c|c|c|c|c|c|c|}
\hline \multicolumn{3}{|c|}{ Cronograma do Projeto } & \multicolumn{12}{|c|}{ Semanas } \\
\hline Etapa & $\begin{array}{l}\text { Duração } \\
\text { Prevista }\end{array}$ & $\begin{array}{c}\text { Duração } \\
\text { Real }\end{array}$ & 1 & 2 & 3 & 4 & 5 & 6 & 7 & 8 & 9 & 10 & 11 & 12 \\
\hline Formalização dos Processos & 10 & 12 & & & & & & & & & & & & \\
\hline Planejamento & 2 & 3 & & & & & & & & & & & & \\
\hline Identificação dos stakeholders & 2 & 2 & & & & & & & & & & & & \\
\hline Criação de formulários & 1 & 1 & & & & & & & & & & & & \\
\hline Cadastramento de itens no sistema & 7 & 8 & & & & & & & & & & & & \\
\hline Treinamento dos stakeholders & 3 & 4 & & & & & & & & & & & & \\
\hline Operar em ambiente de teste & 1 & 3 & & & & & & & & & & & & \\
\hline Implementar & 1 & 3 & & & & & & & & & & & & \\
\hline Legenda & & & & \multicolumn{5}{|c|}{ Concluído } & & \multicolumn{5}{|c|}{ Atraso } \\
\hline
\end{tabular}

Fonte: Documentação interna da empresa (2015)

Inicialmente o trabalho foi programado para ser concluído em dez semanas, contudo em virtude de problemas, como resistências às mudanças e dificuldades na adaptação de novos métodos 
de trabalho, houve um atraso de duas semanas na conclusão do projeto. Os novos métodos de trabalho exigiram mudanças comportamentais na estrutura da empresa, na medida em que muitos dos processos deixaram de ser informais para se tornarem formais.

Conforme observado nas obras de Chu (2003); Senge et al (1999); Gusberti (2015) e Drummond (2015) toda mudança com elevada magnitude, requer da organização um período para transpassar as resistências e se adaptar as mudanças sugeridas. Drumond (2015) enfatiza que as resistências possibilitam oportunidades de repensar os modelos de gestão de mudança, gerando debates salutares que geram decisões mais estruturadas.

Neste sentido, a empresa ofereceu, durante seis meses, treinamentos regulares com os líderes de setores e com operadores de produção com o intuito de fortalecer os conceitos e as mudanças aprendidas com os treinamentos ministrados durante a fase de implementação.

Com objetivo de mensurar os resultados obtidos após a implementação do trabalho, a direção da empresa elencou dez atributos/ indicadores que deveriam ser comparados antes e após a implementação. Para que fatores como sazonalidade não influenciassem a metodologia de mensuração dos dados, foi decidido que a as medições deveriam ser feitas no mesmo mês, com intervalo de um ano entre as medições. A direção da empresa adotou como critério para a validação do trabalho que ao menos seis atributos/ indicadores tivessem um desempenho melhor do que o anterior.

A formalização proposta para os processos da empresa, ou seja, a transformação dos processos tácitos em explícitos teve o propósito de tornar as operações previsíveis, controláveis e perfeitamente compartilháveis, oferecendo a cada um dos gestores e colaboradores, a conscientização acerca da real importância das suas atividades e o seu ajustado sequenciamento.

De acordo Thiel (2015), se em uma empresa não há conhecimento comum, não existe razão para ser uma empresa.

Mensalmente a organização efetuava seus controles internos baseados nos indicadores de desempenho previamente estabelecidos e constatava uma evolução considerável na gestão dos processos, contudo ainda faltava a mensuração derradeira, que validaria ou não o trabalho.

Para Rodrigues e Pinheiro (2015), mudanças envolvem aspectos tecnológicos, estratégicos, estruturais e culturais (comportamentos e habilidades), a modernização dos processos produtivos e alterações na forma de alocação de recursos, precisam ser monitoradas para a verificação da eficácia de tais medidas. Neste sentido, o Quadro 8 consolida a mensuração efetuada antes e após a implementação das propostas. Conforme se pode depreender, a organização obteve melhora em todos os indicadores.

Quadro 8 - Indicadores de Desempenho

\begin{tabular}{|c|l|c|c|c|c|}
\hline Item & \multicolumn{1}{|c|}{ Descrição } & $\begin{array}{c}\text { Unid. de } \\
\text { medida }\end{array}$ & Nov/14 & Nov/15 & $\Delta$ \\
\hline 1 & Atraso nas entregas das Ordens de Produção & Unidade & 48 & 11 & $-77 \%$ \\
\hline 2 & Horas gastas em retrabalho & Horas & 45 & 3 & $-93 \%$ \\
\hline 3 & Reclamação do cliente por falta de material & Unidade & 9 & 1 & $-89 \%$ \\
\hline 4 & Sucata proveniente de retrabalho & Kg & 234 & 28 & $-88 \%$ \\
\hline 5 & Reclamação do cliente por problemas de qualidade & Unidade & 8 & 0 & $-100 \%$ \\
\hline 6 & Ordens de Produção em divergência com a ordem de compra & Unidade & 15 & 2 & $-87 \%$ \\
\hline 7 & Ordens de Produção com consumo acima do especificado & Unidade & 46 & 3 & $-93 \%$ \\
\hline 8 & Consumo de chapas acima do especificado & Kg & 2543 & 125 & $-95 \%$ \\
\hline 9 & Horas paradas por falta de material & Horas & 234 & 8 & $-97 \%$ \\
\hline 10 & Média de tempo para faturamento de uma Ordem & Dias & 15 & 5 & $-67 \%$ \\
\hline
\end{tabular}

Fonte: Documentação interna da empresa (2015) 
Os resultados apontados na melhoria da gestão da empresa, ilustrados no Quadro 8, a partir da realização do presente do estudo, evidenciam que a pesquisa proposta conseguiu atingir os objetivos pretendidos. É válido destacar que diante desse resultado que excedeu as expectativas da empresa, apresentando melhora em todos os indicadores, a diretoria validou e aprovou a proposta.

\section{CONCLUSÕES E SUGESTÕES DE ESTUDOS FUTUROS}

O presente estudo analisou o caso de uma empresa produtora de dutos industriais, especificamente, analisando os impactos deletérios da falta de formalização de processos nos custos e na gerência de operações da referida empresa. Foram feitas propostas de formalização dos processos produtivos, uma vez que os referidos processos eram, em sua maioria, processos conduzidos de forma tácita, tornando-os praticamente incontroláveis.

Cumpre destacar que as propostas foram acolhidas e implementadas pela empresa e os resultados preliminares pós-implantação evidenciaram ganhos de consistentes de produtividade e eficiência, o que sugere que o estudo pode ser utilizado como inspiração para futuros trabalhos e/ ou intervenções técnicas em empresas de manufatura de pequeno porte que experimentem problemas similares, respeitadas as singularidades de cada caso.

Como sugestão adicional para estudos futuros, recomenda-se uma aferição anual do impacto no faturamento e lucratividade da empresa, verificando em que medida essa alteração nos indicadores financeiros é derivada das mudanças na forma de gestão das operações da companhia.

\section{REFERÊNCIAS}

ALBUQUERQUE, J. P. Flexibilidade e modelagem de processos de negócio: uma relação multidimensional. Rev. adm. empres., São Paulo, v. 52, n. 3, p. 313-329, June 2012.

ABPMP. BPM CBOK V3.0. guide to the business process management common body of knowledge. 2. ed. Brasil: Association of Businees Process Management Professsionals Brasil, 2014.

BRANDÃO, C. R.; BORGES, M. C. A pesquisa participante: um momento da educação popular. São Paulo: Ed. Popular. 2007.

BREMER, C.; F.; LENZA, R. de P. Um modelo de referência para gestão da produção em sistemas de produção assembly to order-ATO e suas múltiplas aplicações. Gestão \& Produção, v. 7, n. 3, p. 269-282, 2000.

CORRÊA, H. L.; GIANESI, I.G.N; CAON, M.. Planejamento, programação e controle da produção. São Paulo: Atlas, v. 1, 2001.

CHU, K. F. An organizational culture and the empowerment for change in SMEs in the Hong Kong manufacturing industry. Journal of Materials Processing Technology 139, pp. 505-509, 2003.

DEMO, P. Pesquisa participante: saber pensar e intervir juntos. Brasília: Liber Livro, 2008.

DRUMMOND, P. M. Análises dos resultados comportamentais da implantação de ERP de alta complexidade: uma investigação episódica sob a ótica de gestão de mudanças junto a implementadores e usuários. Dissertação (Mestrado em Sistema de Gestão). Niterói: Universidade Federal Fluminense, 2015.

GONÇALVES, J. E. L. Processo, Que Processo? RAE - Revista de Administração de Empresas. São Paulo, v. 40, n. 4. Out./Dez., 2000.

GUSBERTI, T. D. H., ECHEVESTE, M. E. S.; MOUTINHO SILVA, M.C.; FACCHINI, A. R. Gestão baseada em capacidades para novas empresas de base tecnológica: framework para gestão do processo de conversão de tecnologias. Gestão \& Produção, vol.22 no.4 São Carlos Oct./Dec. 2015

JESTON, J.; NELIS, J. Business Process Management: Practical Guidelines to Successful Implementations. 2 ed. Oxford: Elsevier, 2008. 
KIPPER, L. M. Gestão por Processos: comparação e análise entre metodologias para implantação da gestão orientada a processos e seus principais conceitos. Tecno-Lógica, vol. 15, n.2, p. 89-99, jul./dez. 2011.

KLUSKA, R. A; LIMA, E.P; GOUVÊA, S. E. Uma proposta de estrutura e utilização do gerenciamento de processos de negócio (BPM). Revista Produção Online, Florianópolis, SC, v.15, n. 3, p. 886-913, jul./set. 2015.

KNOFF, L. C. Mapeamento de publicações científicas sobre estratégia de manufatura: uma abordagem baseada em processos. Revista Produção Online, v. 14, n. 2, p. 403-429, 2014.

MARCONI, M. A.; LAKATOS, E. M. Fundamentos da Metodologia. 6 Ed. São Paulo, Atlas, 2007.

MARTINS, P. G.; LAUGENI, F. P. Administração da produção. São Paulo: Saraiva, 2009.

NEUMANN, C. Gestão de sistemas de produção e operações. Rio de Janeiro: Elsevier, 2013.

NUNES, D. M; FACCIO, K. Avaliação fatores chave implementação lean office. Produto \& Produção, v. 15, n. 4, p. 01-16, 2014

OLIVEIRA, D. P. R. Sistemas, Organização \& Métodos (O\&M - Uma Abordagem Gerencial). São Paulo: Atlas, 2002.

PEINADO, J.; GRAEML, A.R. Administração da produção: operações industriais e de serviços. Curitiba: UnicenP, 2007.

PERUSSI FILHO, ESCRIVÃO FILHO. Processo de criação de estratégia em pequenas empresas de base tecnológica: um modelo de fases evolutivas para o setor médico-odontológico. Gestão \& Produção, v. 19, n. 1, p. 173-188, 2012.

ROBBINS, S. P. Comportamento Organizacional. São Paulo: Pearson Prentice Hall, 2005.

RODRIGUES, E.; PINHEIRO, M.; A. - Saraiva. Tecnologia da informação e mudanças organizacionais. Revista de Informática Aplicada, v. 1, n. 2, 2015.

SENGE, P., KLEINER, A., ROBERTS, CROSS, R., ROTH, G., SMITH, B. A dança das mudanças: os desafios de manter o crescimento e o sucesso em organizações que aprendem. Rio de Janeiro: Campus, 1999.

SLACK, N.; CHAMBERS, S.; HARLAND, C., HARRISON, A.; JOHNSTON, R. Administração da Produção. São Paulo: Atlas, 2009.

THIEL, E. E. Proposta de modelo de implantação de um projeto de gestão do conhecimento com base em processos organizacionais. 2002. Tese (Mestrado em Engenharia da Produção) - Programa de Pós-Graduação em Engenharia de Produção do Centro Tecnológico da Universidade Federal de Santa Catarina, Florianópolis. 2015.

TUBINO, D. F. Planejamento e controle da produção: teoria e prática. Editora Atlas SA, 2007. 